\title{
Vascular endothelial growth factor-A and chemokine ligand (CCL2) genes are upregulated in peripheral blood mononuclear cells in Indian amyotrophic lateral sclerosis patients
}

\author{
Pawan K Gupta ${ }^{\dagger}$, Sudesh Prabhakar ${ }^{\dagger}$, Chandrika Abburi, Neel K Sharma and Akshay Anand ${ }^{*}$
}

\begin{abstract}
Background: We have earlier shown that protein levels of vascular endothelial growth factor-A (VEGF-A) and chemokine ligand-2 (CCL2) were elevated in Indian amyotrophic lateral sclerosis (ALS) patients. Here, we report the mRNA levels of VEGF-A and CCL2 in Indian ALS patients since they display extended survival after disease onset.

Methods: VEGF-A and CCL2 mRNA levels were measured in peripheral blood mononuclear cells (PBMCs) of 50 sporadic Indian ALS patients using Real Time Polymerase Chain Reaction (PCR) and compared with normal controls $(n=50)$. Their levels were adjusted for possible confounders like cigarette smoking, alcohol and meat consumption.

Results: VEGF-A and CCL2 mRNA levels were found to be significantly elevated in PBMCs in ALS patients as compared to controls. PBMCs from definite ALS revealed higher VEGF-A mRNA expression as compared to probable and possible ALS. CCL2 mRNA levels were found to be unaltered when definite, probable and possible ALS were compared. PBMCs from patients with respiratory dysfunction showed much higher VEGF-A and CCL2 elevation when compared to patients without respiratory dysfunction. No association of smoking, alcohol and meat consumption with VEGF-A and CCL2 was observed after analyzing the data with univariate and multivariate analysis.
\end{abstract}

Conclusion: VEGF-A and CCL2 mRNA upregulation in PBMCs may have a clinico-pathological/etiological/ epidemiological association with ALS pathogenesis. The cross-cultural and cross-ethnic investigations of these molecules could determine if they have any role in enhancing the mean survival time unique to Indian ALS patients.

\section{Introduction}

Amyotrophic lateral sclerosis (ALS) is a neurodegenerative disorder characterized by selective loss of motor neuron. Vascular endothelial growth factor-A (VEGF-A) is a dimeric secreted polypeptide that was discovered first in the VEGF family which also includes placental growth factor (PLGF), VEGF-B, VEGF-C, VEGF-D and VEGF-E. VEGF-A stimulates growth of blood vessels during embryonic development and helps in proliferation of

\footnotetext{
* Correspondence: akshay1anand@rediffmail.com + Contributed equally

Department of Neurology, Post Graduate Institute of Medical Education and Research (PGIMER), Chandigarh-160012, India
}

blood collaterals in diseased conditions including ALS through a tyrosine kinase dependent VEGF receptor-2 (VEGFR2) [1]. Apart from angiogenesis, VEGF-A is suggested to exert direct neuroprotection via VEGFR2 and neuropilin-1 (NP-1) in animal models and patients of various neurodegenerative disorders [2]. Mice having homozygous deletion in hypoxia response element (HRE) of VEGF-A promoter $\left(\mathrm{VEGF}^{\delta / \delta}\right)$ were reported to develop symptoms like classical ALS [3] and conversely, intrathecal transplantation of stem cells overexpressing VEGF-A delays the onset and progression of ALS in superoxide dismutase-1 (SOD1) mutated transgenic mouse by downregulating proapoptotic proteins and activating
C Biomed Central

(C) 2011 Gupta et al; licensee BioMed Central Ltd. This is an Open Access article distributed under the terms of the Creative Commons Attribution License (http://creativecommons.org/licenses/by/2.0), which permits unrestricted use, distribution, and reproduction in any medium, provided the original work is properly cited. 
phosphatidylinositol 3-kinase/protein kinase B (PI3-K/ Akt) anti apoptotic pathway [4]. On the other hand, chemokine ligand-2 (CCL2), a proinflammatory molecule, may impart neuroprotection in ALS against glutamate induced excitotoxicity either by reducing release of glutamate and/or increasing efficiency of astrocytes to clear glutamate at synapses [5].

Indian ALS patients are known to exhibit significantly extended survival duration after disease onset as compared to Western ALS patients [6-8]. We recently reported that augmented biofluids VEGF-A and CCL2 protein may be associated with increased survival duration of Indian ALS patients [9]. We now measured the mRNA expression of VEGF-A and CCL2 in peripheral blood mononuclear cells (PBMCs) of these patients.

\section{Subjects and methods}

50 patients, born in North India and diagnosed with ALS were included from a convenience sample of Neurology outpatient, post graduate institute of medical education and research (PGIMER), Chandigarh after obtaining informed consent as a part of research proto$\mathrm{col}$ as per institute ethical committee guidelines (No. 7055-PG-1Tg-05/4348-50). Based on the "El Escorial criteria", there were 25 definite ALS patients, 15 individuals were probable ALS and remaining 10 were possible ALS at the time of sample collection. ALS-functional rating score-revised (ALSFRS-R) revealed that 11 patients had respiratory dysfunction such as orthopnea and dyspnea accompanied with other respiratory insufficiencies, although none of the patients needed respiratory support [10]. ALS patients with history of diabetic neuropathy, glaucoma, pre-eclampsia, stroke, those receiving riluzole, anti inflammatory drugs, antioxidants or other treatment were excluded. 50 genetically unrelated healthy normal controls without any apparent health problems such as hypertension, diabetes, heart disease etc were included for comparison. The subjects were categorized as cigarette smokers and never smokers, alcohol consumers and nonalcoholics, vegetarian and non-vegetarian (or meat consumers) using a standard questionnaire as per published criteria [11]. The clinical and demographic details of subjects published earlier [9] have also been reproduced here in Table 1.
PBMCs were isolated as per Histopaque-1077 (Sigma, USA) datasheet. Briefly, $6.0 \mathrm{ml}$ blood was collected from each subject and layered on equal volume of Histopaque-1077. It was then centrifuged at $1800 \mathrm{rpm}$ for 30.0 mins at room temperature and PBMCs were collected from plasma/Histopaque-1077 interface and preserved in RNA later (Sigma, USA) at $-80^{\circ} \mathrm{C}$ until used.

Total RNA was extracted from PBMCs using RNAeasy columns (Qiagen, USA). RNA concentration was measured by taking absorbance at $260.0 \mathrm{~nm}$. About $500.0 \mathrm{ng}$ - 5000.0 ng total RNA was used to synthesize cDNA according to RevertAid ${ }^{\mathrm{TM}}$ first strand cDNA kit (Fermentas, USA).

Real Time Polymerase Chain Reaction (PCR) was used to quantitate expression of VEGF-A and CCL2 mRNA using published primers [12-14]. Methodology of Real Time PCR has been elaborated in "Additional File 1".

Because the data was normally distributed as indicated by quintile-quintile (Q-Q) plot, unpaired, independent, 2-tailed student $t$ test and one-way analysis of variance (ANOVA) followed by Fisher's least significant difference (LSD) post hoc analysis was applied for statistical comparisons. Crude and adjusted odds ratio (OR) was evaluated by univariate and multivariate logistic regression respectively to check any possible influence of smoking, alcohol and meat consumption on VEGF-A and CCL2 mRNA levels and $\chi^{2}$ (chi square) test was performed to find significance level.

$p$-value was considered significant at $\leq 0.05$. Statistical analysis was performed by statistical package and service solutions (SPSS) 16 software. Results were analyzed by two independent and masked researchers.

\section{Results}

Real Time PCR indicates that VEGF-A expression is 77fold higher in ALS than controls (Figure 1A; $\mathrm{p}=0.0001$ ). CCL2 mRNA has shown an increment of 9.5-fold in ALS than controls (Figure 1B; $p=0.005$ ). There was elevated VEGF-A mRNA expression in definite ALS patients in comparison to controls, probable and possible ALS (Figure $2 \mathrm{~A} ; \mathrm{p}=0.0001, \mathrm{p}=0.029$ and $\mathrm{p}=0.018$ respectively). Further, both probable and possible ALS patients were shown to have higher VEGF-A than controls (Figure 2A; $\mathrm{p}$ $=0.0001$ and $p=0.0001$ respectively). However, CCL2

Table 1 Characteristics of the subjects

\begin{tabular}{|c|c|c|c|c|c|c|c|c|}
\hline Subjects & Age $(y)^{\dagger}$ & $M / F(n)$ & Age of onset $(y)$ & Disease duration $^{\ddagger}(\mathrm{mo})$ & $B / L(n)$ & Smokers (n) & Alcohol consumers (n) & Non-vegetarian (n) \\
\hline ALS & $47.4 \pm 12.4$ & $38 / 12$ & $46.2 \pm 12.8$ & $19.0 \pm 12.7$ & $8 / 42$ & 12 & 12 & 20 \\
\hline Controls & $40.0 \pm 12.8$ & $39 / 11$ & & & & 10 & 14 & 27 \\
\hline
\end{tabular}

Clinical and demographic details of subjects. ALS, amyotrophic lateral sclerosis; $n$, Number; $M$, male; $F$, female; $y$, years; mo, months; $B$, bulbar; L, limb; Age, age of onset, duration of disease are indicated as mean \pm standard deviation (SD). + Unpaired, independent 2-tailed student $t$ test analysis showed that mean age differ significantly among the groups $(p=0.004)$. $\neq$ Duration of disease is the interval between appearance of first symptom of ALS and collection of sample. ALS subjects were asked to provide all clinical and demographic details at the age of disease-onset. 


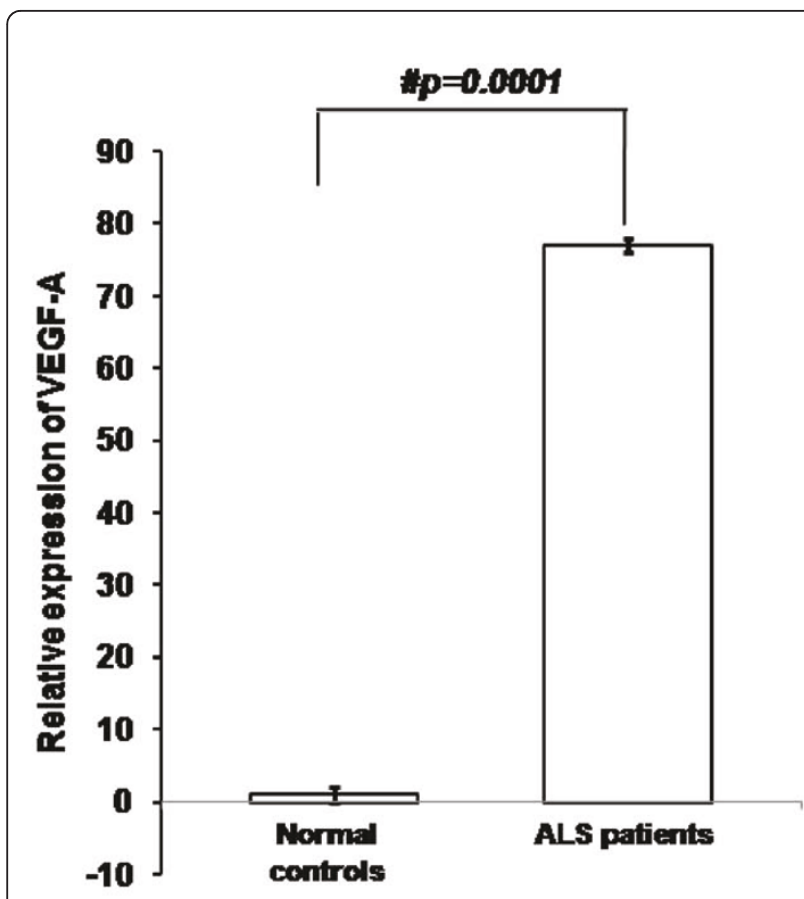

A

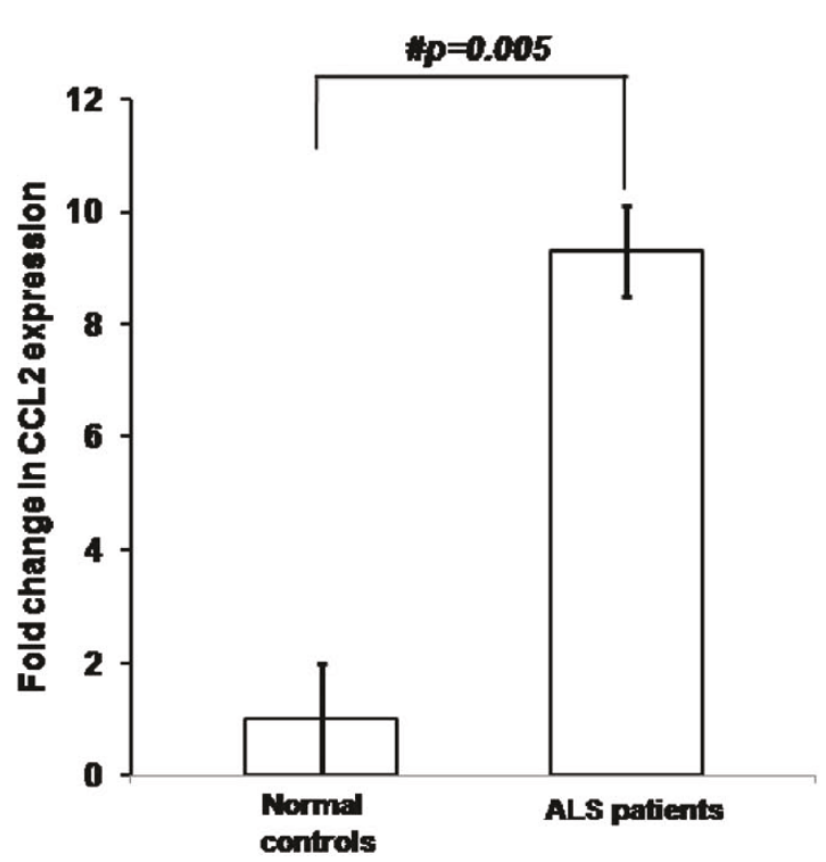

$\mathbf{B}$

Figure 1 Relative mRNA expression of VEGF-A (A) and CCL2 (B) in PBMCs of ALS patients. Values are plotted as mean \pm SE (Standard error) in the bar diagram. Data was analyzed by unpaired, independent 2-tailed student $t$ test. \# indicates significant difference among the groups $(p<0.05)$. Expression of VEGF-A and CCL2 were normalized to expression of endogenous control b-actin. ALS, amyotrophic lateral sclerosis; VEGF-A, vascular endothelial growth factor-A; CCL2, chemokine ligand-2; PBMCs, peripheral blood mononuclear cells.

levels did not vary between definite, probable and possible ALS cases (Figure 2B; p > 0.05).

To find association of respiratory dysfunction, VEGF$A$ and CCL mRNA levels were reanalyzed among ALS patients with respiratory dysfunction and those without respiratory dysfunction. Significantly increased VEGF-A and CCL2 was observed in ALS patients with respiratory dysfunction as compared to patients without respiratory dysfunction (Figure 3A-B; p $=0.045$ and $\mathrm{p}=0.021$ respectively)

No association of cigarette smoking, alcohol and meat consumption with VEGF-A (Table 2) and CCL2 (data not shown) mRNA was observed upon univariate and multivariate analysis.

\section{Discussion}

It has been reported that median survival duration of Indian ALS patients is $\sim 9$ years after disease onset which is significantly higher as compared to their Western counterparts who survive for 3-6 years after disease onset [6-8]. Because of this contradicting presentation, we investigated the levels of VEGF-A and CCL2 among the Indian ALS patients.

The increased PBMCs VEGF-A and CCL2 expression in our patients may suggest the pathophysiological involvement of circulating monocytes and lymphocytes in ALS. The elevated PBMCs VEGF-A is in contrast to previous reports where a profound downregulation of VEGF-A mRNA in SOD1G93A ALS mouse and significantly reduced serum and cerebrospinal fluid (CSF) VEGF-A in ALS patients was observed possibly because of genetic changes in promoter regions [15-17]. Increased serum and CSF VEGF-A reported earlier in ALS and in its different clinical subtype with limb onset and extended disease duration are in agreement with current results $[18,19]$. However, some studies have failed to detect significant change in serum, plasma and CSF VEGF-A in ALS patients [20,21]. It is believed that the variable study designs including different molecular tools, study power, diverse clinical and genetic spectrum of ALS patients may account for conflicting VEGF-A levels. The increased PBMCs CCL2 is consistent with reports where elevated CCL2 mRNA was observed in spinal cord and skeletal muscles of ALS patient's autopsies and SOD1 mutated ALS mice [14,22].

As VEGF-A and CCL2 are neurotrophic, Indian ALS patients may enhance VEGF-A and CCL2 expression in an attempt to ameliorate excitotoxicity through upregulation of glutamate receptor as reported earlier [5,23]. Increased VEGF-A and CCL2 may promote migration 


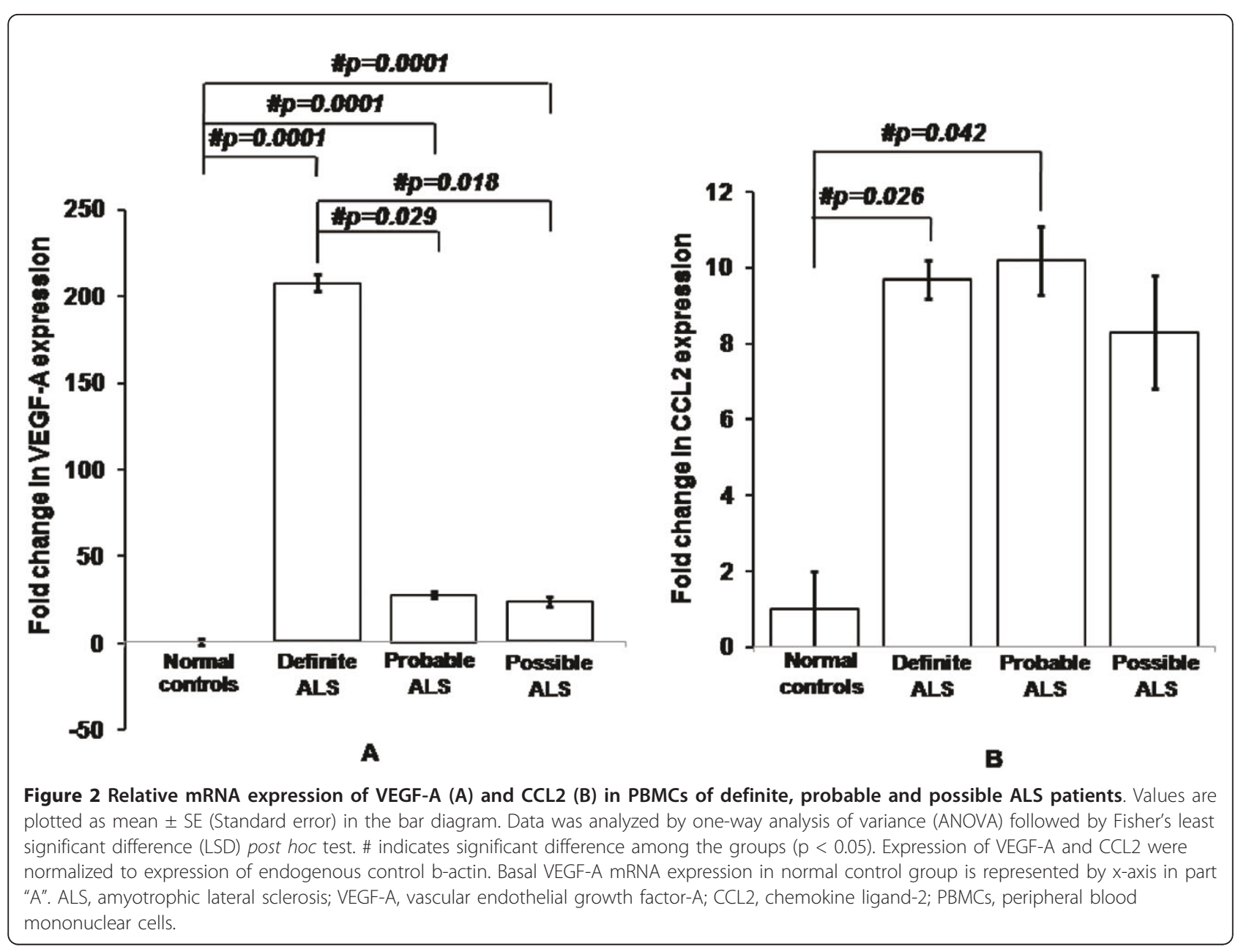

and differentiation of VEGF receptor 1 (VEGFR1), VEGFR2 and chemokine receptor 2 (CCR2) expressing adult neural progenitor cell into neuronal and glial phenotypes at the site of injury [24,25]. Whether their upregulation represent any compensatory response towards extended survival of Indian ALS patients should be evaluated in future comparable cross-cultural and cross-ethnic ALS population where survival is longer. It must be emphasized that mean survival duration of reported ALS patients could not be ascertained.

Since elevated CCL2 initiates inflammatory reaction by increasing production of nitric oxide and other inflammatory chemokines from unregulated monocytes/ macrophages [26] and VEGF-A is known to recruit leukocytes at the site of brain injury by increasing vascular permeability [27], it is possible that the high VEGF-A and CCL2 in our ALS patients may exert limited inflammatory responses associated with neuroprotection [28].

At this moment, we are not able to state whether the increased VEGF-A and CCL2 mRNA is a consequence of genetic and/or epigenetic changes of upstream regulatory sequences, altered transcriptional regulation or amyotrophy and thus the present report lays the foundation for future studies to screen promoter elements of VEGF-A and CCL2 in Indian ALS population for subtle genetic differences. The stress conditions, like respiratory problems, may also modify transcriptional gene regulation as indicated by increased VEGF-A and CCL2 mRNA expression in the 11 ALS patients with respiratory dysfunction and signifies a possible association with hypoxia (Figure 3).

Based on existing literature [29,30], elevated VEGF-A and CCL2 in definite ALS may represent the possibility of relatively extensive extra central nervous system (CNS) involvement and higher degree of nerve endings arborization at neuromuscular junction than probable and possible ALS, however, neuroanatomical architecture of neuromuscular junction has not been evaluated. The possibility of increased VEGF-A and CCL2, in definite ALS due to respiratory dysfunction, may not be ruled out even though only $28 \%$ of all definite ALS cases presented with respiratory symptoms. 


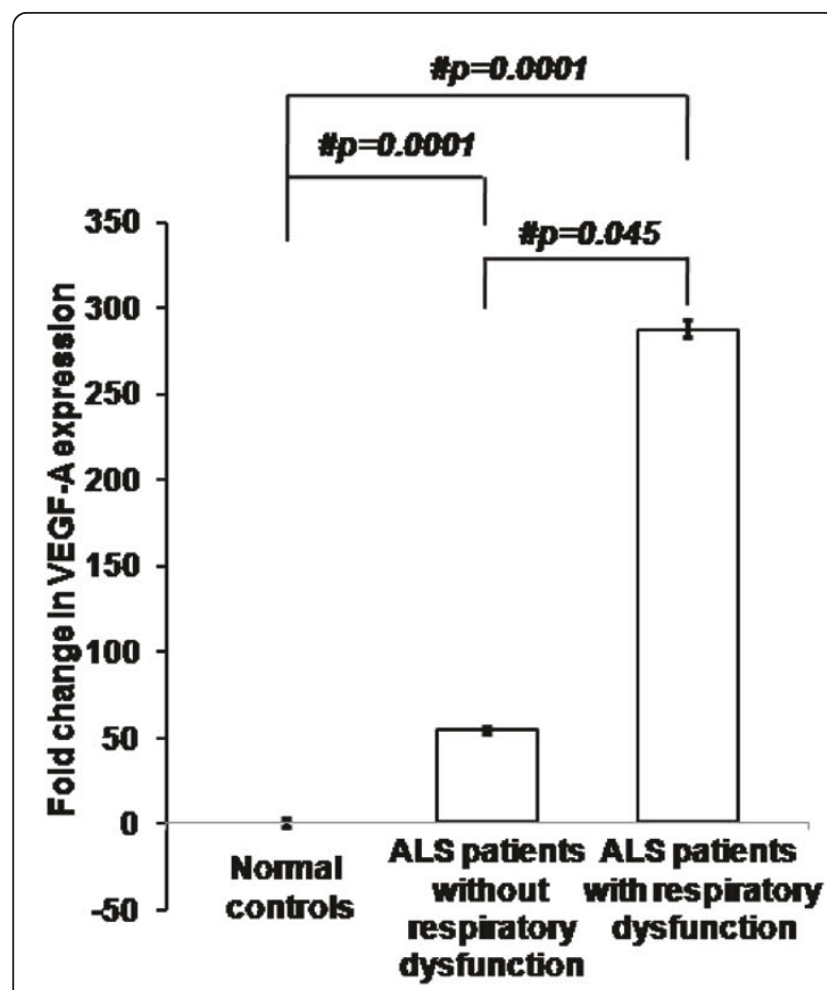

A

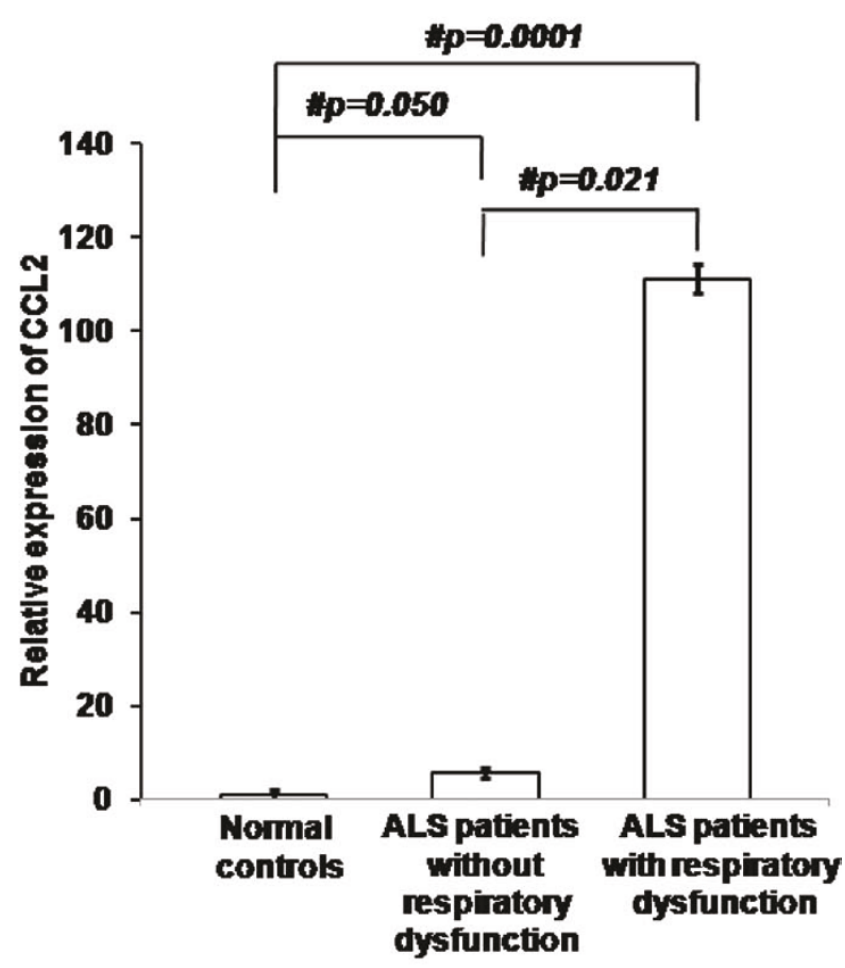

B

Figure 3 Fold change in expression of VEGF-A (A) and CCL2 (B) in PBMCs of ALS patients with respiratory dysfunction. Values are plotted as mean \pm SE (Standard error) in the bar diagram. Data was analyzed by one-way analysis of variance (ANOVA) followed by Fisher's least significant difference (LSD) post hoc test. \# indicates significant difference among the groups $(p<0.05)$. Expression of VEGF-A and CCL2 were normalized to expression of endogenous control b-actin. Basal VEGF-A mRNA expression in normal control group is represented by $x$-axis in part "A". ALS, amyotrophic lateral sclerosis; VEGF-A, vascular endothelial growth factor-A; CCL2, chemokine ligand-2; PBMCs, peripheral blood mononuclear cells.

\section{Conclusion}

Although it can not be concluded that increased VEGFA and CCL2 expression contributes towards enhanced survival yet the importance of clinico-pathological, etiological and epidemiological association of increased

Table 2 Crude and adjusted OR for VEGF-A mRNA

\begin{tabular}{|c|c|c|c|c|}
\hline & OR $(95 \% \mathrm{Cl})^{\dagger}$ & $p^{*}$ & Adj. OR $(95 \% \mathrm{Cl})^{\ddagger}$ & $p^{*}$ \\
\hline \multicolumn{5}{|l|}{ VEGF-A mRNA } \\
\hline Smoking & $0.8(0.2-4.3)$ & 0.8 & $1.1(0.2-6.3)$ & 0.8 \\
\hline Alcohol consumption & $1.0(0.2-4.3)$ & 0.9 & $0.9(0.2-4.5)$ & 0.9 \\
\hline Meat consumption & $0.8(0.2-3.0)$ & 0.8 & $0.8(0.2-3.3)$ & 0.8 \\
\hline Never smoking/ & 1.0 & & 1.0 & \\
\hline \multicolumn{5}{|l|}{ Nonalcoholic/ } \\
\hline \multicolumn{5}{|l|}{ Vegetarian ${ }^{* *}$} \\
\hline \multicolumn{5}{|c|}{$\begin{array}{l}\text { † Univariate logistic regression was used to calculate crude OR. } \neq \text { Multivariate } \\
\text { logistic regression was used to adjust the effect of smoking on VEGF-A mRNA } \\
\text { levels with alcohol and meat consumption as covariates. Likewise, effect of } \\
\text { alcohol and meat consumption on VEGF-A is also adjusted for covariates. }{ }^{*} \chi^{2} \\
\text { (chi square test) was used to test the level of significance. }{ }^{* *} \text { Never smoking, } \\
\text { nonalcoholic and vegetarian diet is considered as reference group. VEGF-A, } \\
\text { vascular endothelial growth factor-A; OR, odds ratio; Cl, confidence interval; } \\
\text { Adj, adjusted. }\end{array}$} \\
\hline
\end{tabular}

VEGF-A and CCL2 with survival of Indian ALS patients may not be underestimated and needs further investigations.

\section{Ethical approval}

Ethical approval was obtained by institute ethical committee, PGIMER, Chandigarh, India - 160012 (No. 7055PG-1Tg-05/4348-50).

\section{Additional material}

Additional file 1: Real Time Polymerase Chain reaction (PCR). Methodology of Real Time PCR; PCR cycling conditions and amplicon size of VEGF-A and CCL2; sequences and references of primers used.

\section{Abbreviations}

ALS: amyotrophic lateral sclerosis; ALSFRS-R: ALS functional rating scorerevised; ANOVA: analysis of variance; CCL2: chemokine ligand-1; CCR2: chemokine receptor-2; CNS: central nervous system; CSF: cerebrospinal fluid; EDTA: ethylene diamine tetraacetate; HRE: hypoxia response element; LSD: least significant difference; mRNA: messenger ribonucleic acid; NMDA: NMethyl-D-aspartate; NP-1: neuropilin-1; OR: odds ratio; PBMCs: peripheral 
blood mononuclear cells; PCR: polymerase chain reaction; PI3-K: phosphatidylinositol 3-kinases; SOD1: superoxide dismutase 1; VEGF: vascular endothelial growth factor; VEGFR1: VEGF receptor-1; VEGFR2: VEGF receptor2.

\section{Acknowledgements}

We acknowledge ICMR (Indian Council of Medical Research), India, for providing funds (No. 5/4 - 5/10/Neuro/2005 - NCD - I).

\section{Authors' contributions}

PKG Acquisition of data and writing of manuscript. SP inclusion of patients, grant PI and clinical scoring. CA Acquisition of data. NKS Statistical analysis, AA Interpretation and analysis of data, grant co PI and writing and editing of manuscript. All authors read and approved the final manuscript.

\section{Competing interests}

The authors declare that they have no competing interests.

Received: 2 May 2011 Accepted: 9 September 2011

Published: 9 September 2011

\section{References}

1. Carmeliet P: Mechanisms of angiogenesis and arteriogenesis. Nat Med 2000, 6:389-395.

2. Storkebaum E, Lambrechts D, Carmeliet P: VEGF: once regarded as a specific angiogenic factor, now implicated in neuroprotection. Bioessays 2004, 26:943-954.

3. Oosthuyse B, Moons L, Storkebaum E, Beck H, Nuyens D, Brusselmans K, Van Dorpe J, Hellings P, Gorselink M, Heymans S, Theilmeier G, Dewerchin $M$, Laudenbach $V$, Vermylen $P$, Raat $H$, Acker T, Vleminckx V, Van Den Bosch L, Cashman N, Fujisawa H, Drost MR, Sciot R, Bruyninckx F, Hicklin DJ, Ince C, Gressens P, Lupu F, Plate KH, Robberecht W, Herbert JM, Collen D, Carmeliet P: Deletion of the hypoxia-response element in the vascular endothelial growth factor promoter causes motor neuron degeneration. Nat Genet 2001, 28:131-138.

4. Hwang DH, Lee HJ, Park IH, Seok JI, Kim BG, Joo IS, Kim SU: Intrathecal transplantation of human neural stem cells overexpressing VEGF provide behavioral improvement, disease onset delay and survival extension in transgenic ALS mice. Gene Ther 2009, 10:1234-1244.

5. Madrigal JL, Leza JC, Polak P, Kalinin S, Feinstein DL: Astrocyte-derived MCP-1 mediates neuroprotective effects of noradrenaline. J Neurosci 2009, 29:263-267.

6. Nalini A, Thennarasu K, Gourie-Devi M, Shenoy S, Kulshreshtha D: Clinical characteristics and survival pattern of 1,153 patients with amyotrophic lateral sclerosis: experience over 30 years from India. J Neurol Sci 2008, 272:60-70.

7. Bradley WG: Commentary on Professor Stephen Hawking's disability advice. Annals of Neurosciences 2009, 16:101-102.

8. Sorenson EJ, Stalker AP, Kurland LT, Windebank AJ: Amyotrophic lateral sclerosis in Olmsted County, Minnesota, 1925 to 1998. Neurology 2002, 59:280-282.

9. Gupta PK, Prabhakar S, Sharma S, Anand A: Vascular endothelial growth factor-A (VEGF-A) and chemokine ligand-2 (CCL2) in Amyotrophic Lateral Sclerosis (ALS) patients. Journal of Neuroinflammation 2011, 8:47.

10. Cedarbaum JM, Stambler N, Malta E, Fuller C, Hilt D, Thurmond B, Nakanishi A: The ALSFRS-R: a revised ALS functional rating scale that incorporates assessmentsof respiratory function. BDNF ALS Study Group (Phase III). J Neurol Sci 1999, 169:13-21.

11. Prabhakar S, Vinish M, Das CP, Anand A: Occurrence of PARK2 Mutations in a Never-Smoker Population with Parkinson's Disease in North India. Neuroepidemiology 2010, 35:152-159.

12. Meister B, Grünebach F, Bautz F, Brugger W, Fink FM, Kanz L, Möhle R: Expression of vascular endothelial growth factor (VEGF) and its receptors in human neuroblastoma. Eur J Cancer 1999, 35:445-449.

13. Ebihara N, Yamagami S, Yokoo S, Amano S, Murakami A: Involvement of CC chemokine ligand 2-CCR2 interaction in monocyte-lineage cell recruitment of normal human corneal stroma. J Immunol 2007, 178:3288-3292.

14. Henkel JS, Engelhardt Jl, Siklos L, Simpson EP, Kim SH, Pan T, Goodman JC, Siddique T, Beers DR, Appel SH: Presence of dendritic cells, MCP-1, and activated microglia/macrophages in amyotrophic lateral sclerosis spinal cord tissue. Ann Neurol 2004, 55:221-235.

15. Lu L, Zheng L, Viera L, Suswam E, Li Y, Li X, Estévez AG, King PH: Mutant $\mathrm{Cu} / \mathrm{Zn}$-superoxide dismutase associated with amyotrophic lateral sclerosis destabilizes vascular endothelial growth factor mRNA and downregulates its expression. J Neurosci 2007, 30:7929-38.

16. Lambrechts D, Storkebaum E, Morimoto M, Del-Favero J, Desmet F, Marklund SL, Wyns S, Thijs V, Andersson J, van Marion I, Al-Chalabi A, Bornes S, Musson R, Hansen V, Beckman L, Adolfsson R, Pall HS, Prats H, Vermeire S, Rutgeerts P, Katayama S, Awata T, Leigh N, Lang-Lazdunski L, Dewerchin M, Shaw C, Moons L, Vlietinck R, Morrison KE, Robberecht W, Van Broeckhoven C, Collen D, Andersen PM, Carmeliet P: VEGF is a modifier of amyotrophic lateral sclerosis in mice and humans and protects motoneurons against ischemic death. Nat Genet 2003, 34:383-394.

17. Devos D, Moreau C, Lassalle P, Perez T, De Seze J, Brunaud-Danel V, Destée $A$, Tonnel $A B$, Just $N$ : Low levels of the vascular endothelial growth factor in CSF from early ALS patients. Neurology 2004, 62:2127-2129.

18. Nygren I, Larsson A, Johansson A, Askmark H: VEGF-A is increased in serum but not in spinal cord from patients with amyotrophic lateral sclerosis. Neuroreport 2002, 13:2199-2201.

19. Hzecka J: Cerebrospinal fluid vascular endothelial growth factor in patients with amyotrophic lateral sclerosis. Clin Neurol Neurosurg 2004, 106:289-93.

20. Cronin S, Greenway MJ, Ennis S, Kieran D, Green A, Prehn JH, Hardiman O: Elevated serum angiogenin levels in ALS. Neurology 2006, 67:1833-1836.

21. Nagata T, Nagano I, Shiote M, Narai H, Murakami T, Hayashi T, Shoji M, Abe K: Elevation of MCP-1 and MCP-1/NEGF ratio in cerebrospinal fluid of amyotrophic lateral sclerosis patients. Neurol Res 2007, 29:772-776.

22. Manzano R, Toivonen JM, Oliván S, Calvo AC, Moreno-lgoa M, Muñoz MJ, Zaragoza P, García-Redondo A, Osta R: Altered Expression of Myogenic Regulatory Factors in the Mouse Model of Amyotrophic Lateral Sclerosis. Neurodegener Dis 2011, 8:386-396.

23. Bogaert E, Van Damme P, Poesen K, Dhondt J, Hersmus N, Kiraly D, Scheveneels W, Robberecht W, Van Den Bosch L: VEGF protects motor neurons against excitotoxicity by upregulation of GluR2. Neurobiol Aging 2010, 31:2185-2191.

24. Meng H, Zhang Z, Zhang R, Liu X, Wang L, Robin AM, Chopp M: Biphasic effects of exogenous VEGF on VEGF expression of adult neural progenitors. Neurosci Lett 2006, 393:97-101.

25. Liu XS, Zhang ZG, Zhang RL, Gregg SR, Wang L, Yier T, Chopp M: Chemokine ligand 2 (CCL2) induces migration and differentiation of subventricular zone cells after stroke. J Neurosci Res 2007, 85:2120-2125.

26. Zhao W, Xie W, Le W, Beers DR, He Y, Henkel JS, Simpson EP, Yen AA, Xiao Q, Appel SH: Activated microglia initiate motor neuron injury by a nitric oxide and glutamate-mediated mechanism. J Neuropathol Exp Neurol 2004, 63:964-977.

27. Bartholdi D, Rubin BP, Schwab ME: VEGF mRNA induction correlates with changes in the vascular architecture upon spinal cord damage in the rat. Eur J Neurosci 1997, 9:2549-2560.

28. Rosenstein JM, Krum JM: New roles for VEGF in nervous tissue-beyond blood vessels. Exp Neurol 2004, 187:246-253.

29. Zheng C, Sköld MK, Li J, Nennesmo I, Fadeel B, Henter Jl: VEGF reduces astrogliosis and preserves neuromuscular junctions in ALS transgenic mice. Biochem Biophys Res Commun 2007, 363:989-993.

30. Cui LY, Liu MS, Tang XF: Single fiber electromyography in 78 patients with amyotrophic lateral sclerosis. Chin Med J (Engl) 2004, 117:1830-1833.

\section{doi:10.1186/1742-2094-8-114}

Cite this article as: Gupta et al.: Vascular endothelial growth factor-A and chemokine ligand (CCL2) genes are upregulated in peripheral blood mononuclear cells in Indian amyotrophic lateral sclerosis patients. Journal of Neuroinflammation 2011 8:114. 